\title{
Cooperative effect of cobalt and zeolite in controlling activity and stability of a catalytic Fischer-Tropsch process
}

\author{
Liliya V. Sineva ${ }^{1}$ - Ekaterina Yu. Asalieva ${ }^{1}$ Ekaterina V. Kulchakovskaya ${ }^{1} \cdot$ Kirill O. Gryaznov $^{1}$. \\ Vladimir Z. Mordkovich ${ }^{1}$ (1)
}

Received: 31 July 2019 / Accepted: 21 January 2020 / Published online: 20 February 2020

(C) The Author(s) 2020

\begin{abstract}
The use of zeolites in Co-catalysts of Fischer-Tropsch synthesis (FTS) results in cooperative effect in the form of sudden increase of the zeolite activity in catalysing secondary transformations of FTS-generated hydrocarbons at unusually low temperatures in the range of $170-260^{\circ} \mathrm{C}$. In addition, hydrophobic zeolites in $\mathrm{H}$-form allow changing the hydrophobicity of the pore walls and influence capillary condensation phenomena for intermediate species. The most unexpected effect of Co and hydrophobic zeolites is the improvement of degradation behaviour of the catalysts due to involvement of FTS-generated water into formation of additional Bronsted centres thus preventing undesirable oxidation of heat-conductive metal additives and other water-induced degradation processes. In addition, the stability of catalyst behaviour and its lifetime increase.
\end{abstract}

Keywords Heterogeneous catalysis $\cdot$ Cobalt $\cdot$ Zeolite $\cdot$ Fischer-Tropsch synthesis $\cdot$ Cooperative effect

\section{Introduction}

Liquid hydrocarbons synthesized from $\mathrm{CO}$ and $\mathrm{H}_{2}$ by Fischer-Tropsch synthesis (FTS) remain one of promising sources of high-quality sulfur-free motor fuels $[1,2]$. The composition of the liquid hydrocarbon mixtures (syncrudes) depends on both the catalyst properties and the process parameters [1-3]. In particular, the common Co-based catalysts on alumina or silica support provide formation of predominantly linear hydrocarbons including high molecular weight compounds aka waxes. To receive drop-in fuels it is necessary to subject such mixture to additional chemical transformations including costly hydrocracking of waxes.

It is very attractive to skip the hydrocracking step in producing syncrude by Fischer-Tropsch method [4-6]. The use of hybrid catalysts where cobalt Fischer-Tropsch active centres are complemented by zeolite acidic cracking centres may help reaching the desirable target. The activity of zeolites in cracking, hydrocracking and other reactions of interest is revealed at the temperatures of $300{ }^{\circ} \mathrm{C}$ and higher, which is too different from the FTS typical temperature

Vladimir Z. Mordkovich

mordkovich@tisnum.ru

1 Technological Institute for Superhard and Novel Carbon Materials, 7A Centralnaya, Troitsk, Moscow 108840, Russia range. This difference in temperature ranges implies that a cobalt-zeolite catalyst should not perform as hybrid one. Despite this argumentation, the works [4-8] report experimental results, which can be interpreted as manifestation of cooperative catalysis effect, i.e. the activity of zeolite centres in secondary transformations of FTS-generated hydrocarbons is much higher than it could be expected.

Such multifunctional catalyst granule should be theoretically capable of generating more product due to lower viscosity of light syncrude as compared with wax-laden classical FTS product. It would require the solution of the main problems of FTS proper, namely high exothermicity and low productivity of a packed catalyst bed. The hybrid catalytic system is to provide heat removal and product transport from the core of the catalyst granules $[9,10]$. One of the ways providing such effect is the introduction of heat-conducting additives such as aluminium metal $[9,11]$. This method is well developed and even used in industrial practice [12].

The understanding of the possible cooperative effect requires revealing that $\mathrm{H}_{2} \mathrm{O}$ is a main FTS by-product, which forms the environment of all the reactions proceeding in a bed as illustrated by main reaction equations shown below:

$n \mathrm{CO}+(2 n+1) \mathrm{H}_{2} \rightarrow \mathrm{C}_{n} \mathrm{H}_{2 n+2}+n \mathrm{H}_{2} \mathrm{O}$, 
$n \mathrm{CO}+2 n \mathrm{H}_{2} \rightarrow \mathrm{C}_{n} \mathrm{H}_{2 n}+n \mathrm{H}_{2} \mathrm{O}$.

There are few ways for the water to get out of the reaction zone; the only $\mathrm{H}_{2} \mathrm{O}$-consuming reaction is the reaction with $\mathrm{CO}$ with formation of $\mathrm{CO}_{2}$ and hydrogen. It is well known that Co has catalytic effect in this reaction although it is limited and conversion dependent [13, 14]. Therefore, the FTS-generated water is accumulated in the reaction bed inspiring oxidation and sintering of active Co particles as well as formation of catalytically inactive cobalt-support compounds. As a result, it often leads to quick degradation determined mostly by the properties of a support and by partial pressure of water vapor (the ratio $p \mathrm{H}_{2} \mathrm{O} / p \mathrm{H}_{2}<1.5$ as a criterion of slower degradation) $[3,15,16]$. The removal of water from the reaction zone can help improving catalyst service life. The negative effect of water is enhanced in case of pelletized catalysts with thermally conductive additives, where the additive (metal flakes or micro-particles) is quickly oxidized by the water $[8,11]$.

The problem of negative effect of water in FTS can be solved by controlling hydrophilicity/hydrophobicity of a catalyst/product interface. Zeolites are known as capable of revealing hydrophilic or hydrophobic properties depending on their form and composition [17-19]. Conventional classification is based on competitive absorption of water from water-hydrocarbon mixtures. Zeolites with high concentration of alkali or alkaline earth cations are hydrophilic as they have high affinity towards polar molecules, which are small enough to enter the zeolite micropores [20]. High silica zeolites absorb preferably hydrocarbons from water-hydrocarbon mixtures, so they are hydrophobic [21-23]. Hydrophobicity can be varied as stipulated in $[17,19,23]$ —so the introduction of a zeolite into FTS catalyst granule can allow controlling catalyst/product interface properties and hence controlling water impact on a catalyst. This suggestion was earlier confirmed for a simpler case of a catalyst based on support-free skeleton Co [24].

The purpose of this work is to reveal a cooperative catalytic effect of $\mathrm{Co}$ and zeolites in impregnation catalysts for Fischer-Tropsch synthesis.

\section{Experimental}

Supports were prepared by extrusion of the paste consisting of aluminium metal powder (RUSAL), zeolite HBeta with $\mathrm{Si} / \mathrm{Al}=19, \mathrm{HY}$ with $\mathrm{Si} / \mathrm{Al}=30$ (both Zeolyst), $\mathrm{CaX}$ with $\mathrm{Si} / \mathrm{Al}=2, \mathrm{NaX}$ with $\mathrm{Si} / \mathrm{Al}=2$ and $\mathrm{CaA}$ with $\mathrm{Si} / \mathrm{Al}=1$ (all ZAO "Nizhegodskie sorbenty" binder (Disperal P2, Sasol) and a liquid phase (the distilled water, nitric acid and triethylene glycol). One type of support was prepared zeolite-free for reference. Diameter of the extruder die was $2.5 \mathrm{~mm}$. Ready extrudates were dried, calcined and cut to
Table 1 Composition of catalysts in \% wt. Co-Ref catalyst was prepared as a reference

\begin{tabular}{llllll}
\hline Catalyst & Cobalt $^{\mathrm{a}}$ & Zeolite & $\mathrm{Al}_{2} \mathrm{O}_{3}$ & & $\mathrm{Al} \mathrm{metal}^{\mathrm{b}}$ \\
\cline { 4 - 6 } & & & & As prepared & $\begin{array}{l}\text { After } \\
\text { catalytic } \\
\text { run }\end{array}$ \\
\hline Co-Ref & 20 & - & 53 & 27 & 11 \\
Co-HBeta & 20 & 24 & 30 & 26 & 24 \\
Co-HY & 20 & 24 & 29 & 27 & 24 \\
Co-CaX & 20 & 24 & 28 & 28 & 12 \\
Co-NaX & 20 & 24 & 27 & 29 & 10 \\
Co-CaA & 20 & 24 & 32 & 24 & 14 \\
\hline
\end{tabular}

${ }^{\mathrm{a}}$ Cobalt content was confirmed by chemical analysis

${ }^{\mathrm{b}} \mathrm{Al}$ metal content was determined by volumetric method (measurement of the volume of hydrogen released in the reaction between a sample and $\mathrm{NaOH}$ aqueous solution). The composition adds up to $100 \%$ accounting the "as-prepared Al metal" column only; while the "after catalytic run" column is shown for comparison

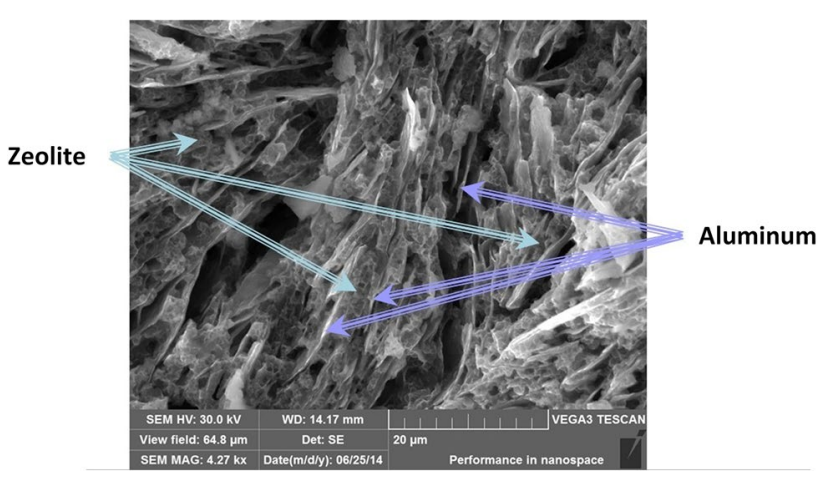

Fig. 1 SEM of the Co-HBeta catalyst fracture. Al metal can be seen in the form of chips or flakes, while zeolite particle are visualized as polyhedrons in between the flakes

$2.2-2.5 \times 2.5-3.0 \mathrm{~mm}$ pellets. All catalysts were prepared by two-step incipient wetness impregnation of supports with water solution of $\mathrm{Co}\left(\mathrm{NO}_{3}\right)_{2} \cdot 6 \mathrm{H}_{2} \mathrm{O}$, every step was followed by calcination in air flow at $250{ }^{\circ} \mathrm{C}$ for $1 \mathrm{~h}$. Cobalt content was $20 \%$ wt. for each catalyst. The composition of catalysts is given in Table 1. SEM picture of a catalyst fracture shows that the zeolite particles are evenly distributed between aluminium metal flakes thus providing a heat-conductive network across the catalyst pellet-see Fig. 1. Catalyst Co-Ref did not contain any zeolite and served as a reference.

Table 2 summarizes data on surface area and pores of the catalysts under investigation. The macropore volume was measured by water pycnometry method, all the other parameters were determined using nitrogen adsorption method. The mesopores were measured in the pore size range 30-1000 A. The influence of a zeolite type on a catalyst structural properties can be understood by the analysis of 
Table 2 Surface area and pores in the catalysts under investigation

\begin{tabular}{llll}
\hline Catalysts & $\begin{array}{l}\text { Macropore vol- } \\
\text { ume, } \mathrm{cm}^{3} / \mathrm{g}\end{array}$ & $\begin{array}{l}\text { Mesopore vol- } \\
\text { ume, } \mathrm{cm}^{3} / \mathrm{g}\end{array}$ & $\mathrm{BET}, \mathrm{m}^{2} / \mathrm{g}$ \\
\hline Ref & 0.228 & 0.138 & 109 \\
Co-HBeta & 0.427 & 0.100 & 155 \\
Co-HY & 0.592 & 0.197 & 192 \\
Co-CaX & 0.638 & 0.128 & 134 \\
Co-NaX & 0.632 & 0.087 & 75 \\
Co-CaA & 0.631 & 0.098 & 93 \\
\hline
\end{tabular}

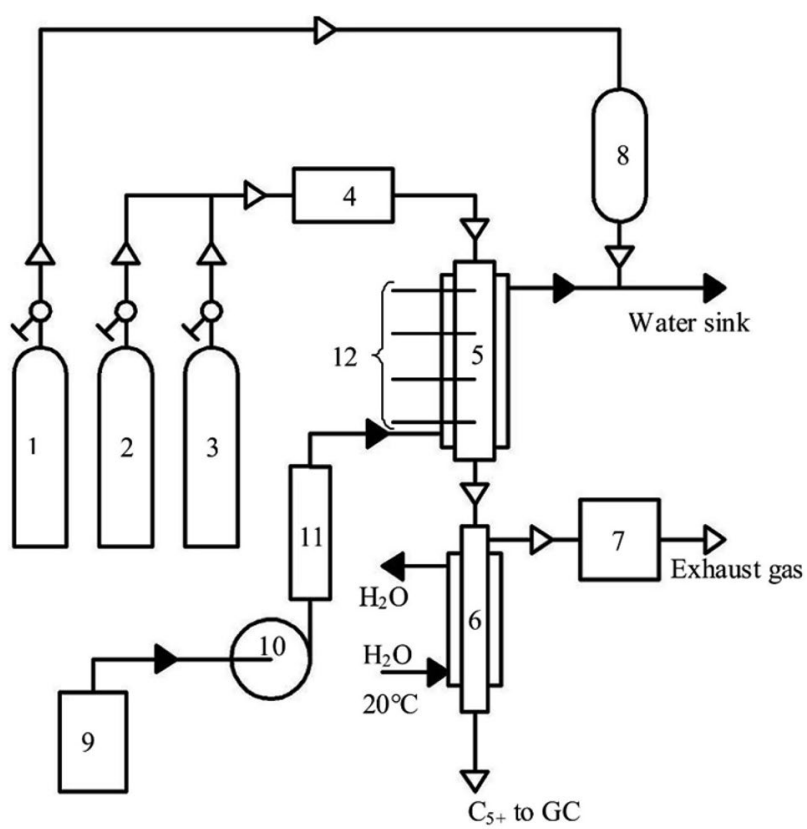

Fig. 2 Flowsheet of a laboratory rig for testing highly productive Fischer-Tropsch catalysts: 1-3-gas cylinders; 4-mass flow controller; 5-reactor; 6-liquid product separator; 7-GC; 8-receiver; 9water supply tank; 10 -water pump; 11 -water heater; 12 -thermocouples

Table 2. Indeed, the introduction of $\mathrm{H}$-form zeolites resulted in macropore volume increase by 1.9-2.5 times, while the cationic forms led to 2.8-fold increase. Mesopore volume decreased as a result of introduction of all the zeolites with single exception of HY. The distinction of $\mathrm{CaA}$ and $\mathrm{NaX}$ was revealed by decrease in the specific surface of a catalyst from $106 \mathrm{~m}^{2} / \mathrm{g}$ down to 93 and $75 \mathrm{~m}^{2} / \mathrm{g}$, respectively.

Fischer-Tropsch catalysts testing was done at $2 \mathrm{MPa}$ in a laboratory test rig (Fig. 2). The temperature of the catalyst bed was maintained by circulation of pressurized pre-heated water through the reactor jacket. The pressure of the circulating water was kept constant, which was 0.5-0.7 MPa higher than the boiling pressure at the reaction temperature. This technical solution provides efficient heat removal at stationary conditions and quenches undesirable effects of hot spot development. In the latter case, the circulating water undergoes phase transition due to hot spot overheat, thus removes an excess heat and returns the bed into the stationary condition. The amount of a sample in this rig was approximately $2.5 \mathrm{~cm}^{3}$, the reactor inner diameter $-11 \mathrm{~mm}$. Syngas with molar ratio of $\mathrm{H}_{2} / \mathrm{CO}=2$ was fed at space velocities of $1000 \mathrm{~h}^{-1}$ and $3000 \mathrm{~h}^{-1}$. Catalysts were activated in hydrogen at $400{ }^{\circ} \mathrm{C}, 0.1 \mathrm{MPa}$ and at gas-hour space velocity (GHSV) of $3000 \mathrm{~h}^{-1}$.

Composition of gaseous and liquid products was determined chromatographically. The analysis of feed mixture and gaseous products $\left(\mathrm{CH}_{4}, \mathrm{CO}_{2}, \mathrm{C}_{2}-\mathrm{C}_{4}\right.$ hydrocarbons $)$ was done by gas adsorption chromatography (thermal conductivity detector, carrier gas-helium, gas flow rate $20 \mathrm{ml} / \mathrm{min}$ ). The column with $\mathrm{CaA}$ molecular sieves $(3 \mathrm{~m} \times 3 \mathrm{~mm})$ was used to separate $\mathrm{CO}$ and $\mathrm{CH}_{4}$. The HayeSep column $(3 \mathrm{~m} \times$ $3 \mathrm{~mm}$ ) was used to separate $\mathrm{CO}_{2}$ and $\mathrm{C}_{2}-\mathrm{C}_{4}$ hydrocarbons. The temperature-programmed mode was used $\left(60-200{ }^{\circ} \mathrm{C}\right.$, heating rate $10^{\circ} \mathrm{C} / \mathrm{min}$ ).

Composition of liquid syncrude was determined by gas-liquid chromatography (flame ionization detector, carrier gas-helium, gas flow rate $30 \mathrm{ml} / \mathrm{min}$ ). The $50 \mathrm{~m}$ length capillary column with DP-Petro plate was used. The temperature-programmed mode was used $\left(50-270{ }^{\circ} \mathrm{C}\right.$, heating rate $4{ }^{\circ} \mathrm{C} / \mathrm{min}$ ). The water- liquid phase was accounted for in calculation of material balance. The water phase contained only negligible amounts of acids/alcohols, which never exceeded 400 ppm.

The material balance closure was achieved in the experiments with accuracy $1 \%$ or better.

\section{Results and discussion}

Experimental results on $\mathrm{CO}$ conversion and $\mathrm{C}_{5+}$ selectivity are shown in Fig. 3 as a function of reaction temperature for GHSV $1000 \mathrm{~h}^{-1}$. It is obvious that temperature influence is drastically different for zeolites in $\mathrm{H}$-form and in cationic form. $\mathrm{CO}$ conversion is higher in the presence of $\mathrm{H}$-zeolites at the temperature below $200{ }^{\circ} \mathrm{C}$. The $\mathrm{C}_{5+}$ selectivity decreases with temperature for $\mathrm{H}$-zeolites while for cationic zeolites it does not depend on temperature. $\mathrm{CO}$ conversion jumps in the temperature range $200-220{ }^{\circ} \mathrm{C}$ for cationic zeolites while $\mathrm{C}_{5+}$ selectivity is still constant. H-zeolites show almost opposite behaviour in that same temperature range. As soon as reaction temperature exceeds $220{ }^{\circ} \mathrm{C}$ the $\mathrm{CO}$ conversion increases for all the catalysts although much slower for cationic zeolites. The $\mathrm{C}_{5+}$ selectivity in the temperature range $220-240{ }^{\circ} \mathrm{C}$ drops down for $\mathrm{H}$-zeolites and stays almost constant for cationic ones. In case of the Ref catalyst, $\mathrm{CO}$ conversion rises with temperature at the temperatures exceeding $200{ }^{\circ} \mathrm{C}$, while $\mathrm{C}_{5+}$ selectivity keeps constant in a wide temperature range. 


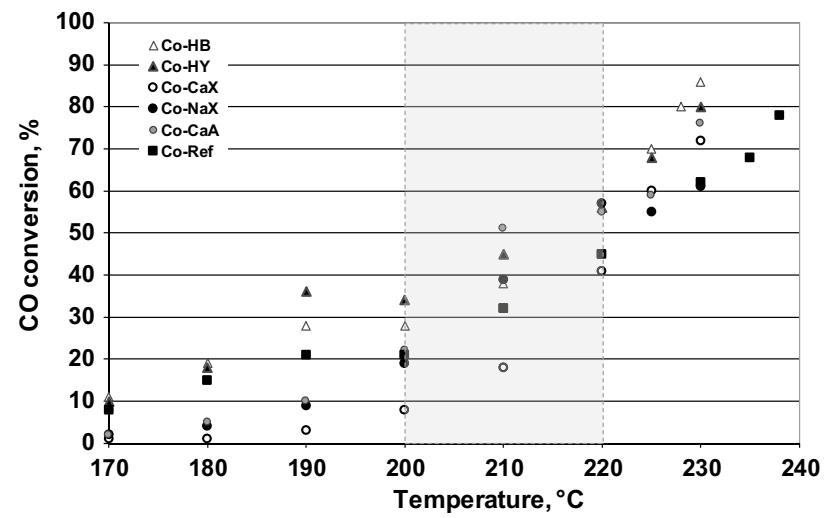

a

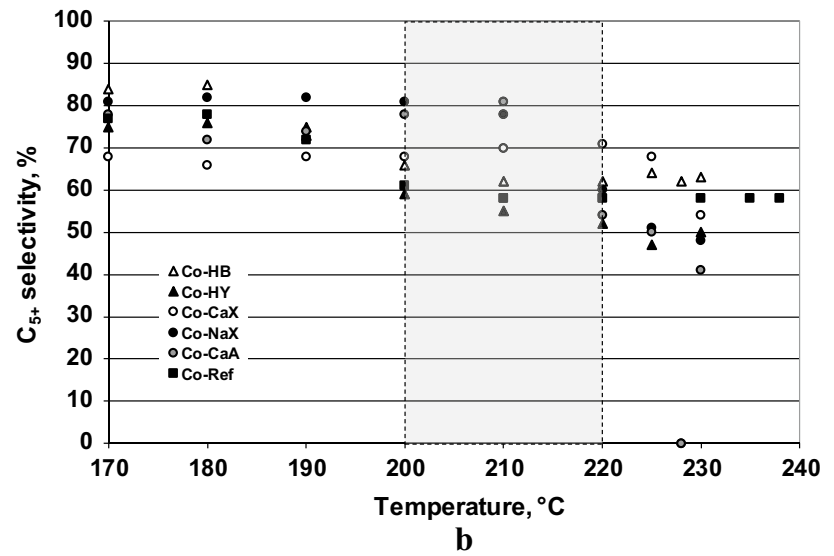

Fig. 3 Influence of reaction temperature on $\mathrm{CO}$ conversion (a) and $\mathrm{C}_{5+}$ selectivity at GHSV $1000 \mathrm{~h}^{-1}$

Methane yield and selectivity are shown in Fig. 4 as a function of the reaction temperature. The methane formation selectivity manifests the most distinctive dependencies with maximum for $\mathrm{H}$-zeolites and monotonous rise for cationic zeolites. The latter also show steeper rise at the temperatures beyond $210^{\circ} \mathrm{C}$. The yield of methane increases through all the temperature range for all the catalysts, however distinctions between zeolite forms are still clear. In particular, the $\mathrm{H}$-zeolites provide linear rise of the $\mathrm{CH}_{4}$ yield at the temperatures below $220{ }^{\circ} \mathrm{C}$ with almost no change at higher temperatures. Unlike that, the cationic form demonstrates the steepest increase at the temperatures beyond $220^{\circ} \mathrm{C}$. In case of Ref catalyst, the temperature dependence of methane selectivity is similar to that for the catalysts with $\mathrm{H}$-for zeolites and very different from the catalysts with cationic form zeolites.

We believe that these results can be explained on the basis of competitive water/hydrocarbon adsorption, which influences capillary condensation of both water and hydrocarbons. The suggestion is that $210{ }^{\circ} \mathrm{C}$ is the temperature of water release from the pores of the catalyst. It means that this release of the capillary-condensed liquid results in intensification of mass transport in the catalysts containing

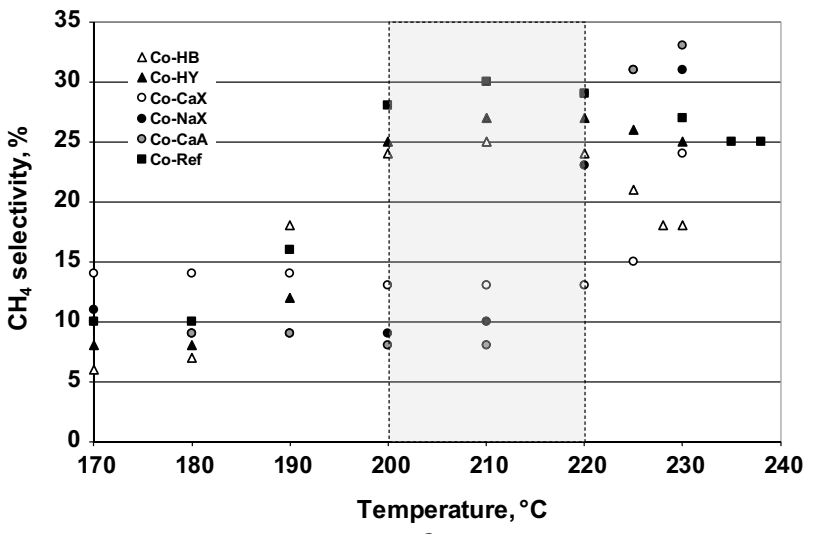

a

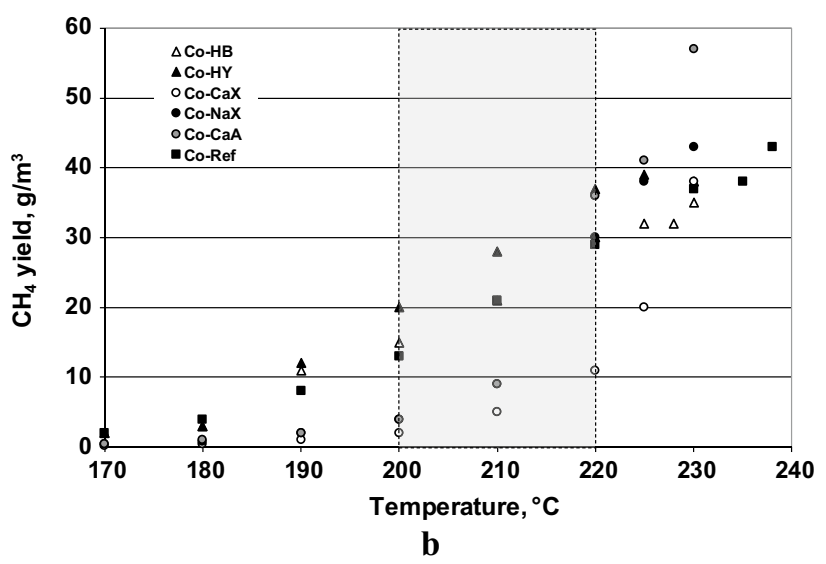

Fig. 4 Influence of reaction temperature on methane selectivity (a) and methane yield at GHSV $1000 \mathrm{~h}^{-1}$

H-zeolites. Unlike that, the cationic zeolites keep water in the pores at higher temperatures due to adsorptive and Coulomb forces. This explains difference in catalysis in the temperature range of $200-220{ }^{\circ} \mathrm{C}$ between catalysts with $\mathrm{H}$-zeolites and with cationic zeolites. Above $220^{\circ} \mathrm{C}$ in the presence of $\mathrm{H}$-zeolites a mass exchange is further intensified. Thanks to involvement of Bronsted centers into secondary transformations of hydrocarbons thus promoting promotes higher activities and productivities. At the same time water serves as a source of additional Bronsted centers [25-27], also promoting an intensification of a mass exchange and increase in activity and productivity.

Figure 5a allows comparing Fischer-Tropsch synthesis parameters at $1000 \mathrm{~h}^{-1}$ for different catalysts. It is obvious that the catalysts with cationic forms of zeolites are characterized by lower $\mathrm{CO}$ conversion and productivity. The catalysts with $\mathrm{H}$-form zeolites performed better. Apparently, the reference catalyst was not much different at this particular GHSV.

The distinction of the catalysts with zeolites became evident at higher GHSV as can be seen from Fig. 5. In particular, the $\mathrm{CO}$ conversion over reference catalyst dropped 


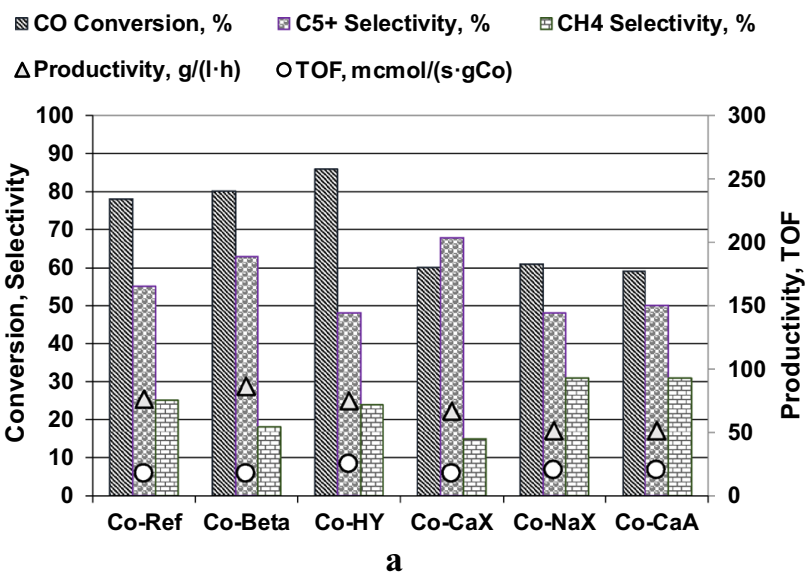

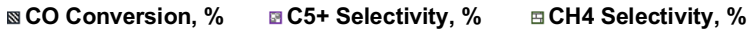
$\Delta$ Productivity, $\mathrm{g} /(\mathbf{l} \cdot \mathrm{h}) \quad$ OTOF, $\mathrm{mcmol} /(\mathrm{s} \cdot \mathrm{gCo})$

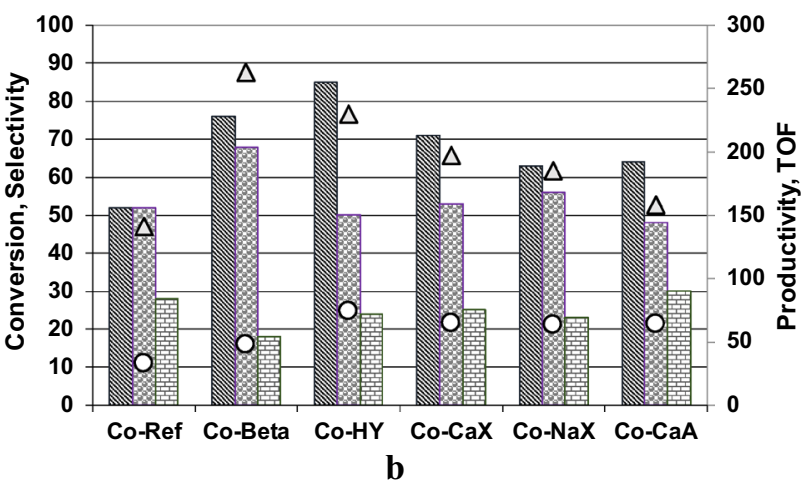

Fig. 5 FTS parameters of the catalysts with different zeolite forms at GHSV $1000 \mathrm{~h}^{-1}$ and $3000 \mathrm{~h}^{-1}$

by $30 \%$ after GHSV increase up to $3000 \mathrm{~h}^{-1}$; while Hbeta demonstrated unchanged $\mathrm{CO}$ conversion and threefold jump in productivity.

The experiments at higher GHSV of $3000 \mathrm{~h}^{-1}$ showed that the most active and productive catalysts are those based on zeolites in H-form-see Fig. 5b. The comparison of the productivity values with turn over frequency (TOF) suggests that the Co activity does not depend on a bed productivity, which is explained by contribution of diffusion limitations, which is typical for a trickle-bed Fischer-Tropsch process. One can also observe that the methane selectivity is determined primarily by a catalyst composition not $\mathrm{CO}$ conversion.

The composition of FTS-generated syncrude $\mathrm{C}_{5+}$ depended first on the form of a zeolite, namely the presence of $\mathrm{H}$-zeolites resulted in higher content of olefins, isoparaffins and $\mathrm{C}_{5}-\mathrm{C}_{10}$ fraction-see Fig. 6 . It is necessary to note that the content of the heaviest fraction $\mathrm{C}_{19+}$ was almost negligible in case of $\mathrm{H}$-zeolites, which witnesses strong contribution of cracking. These observations are in
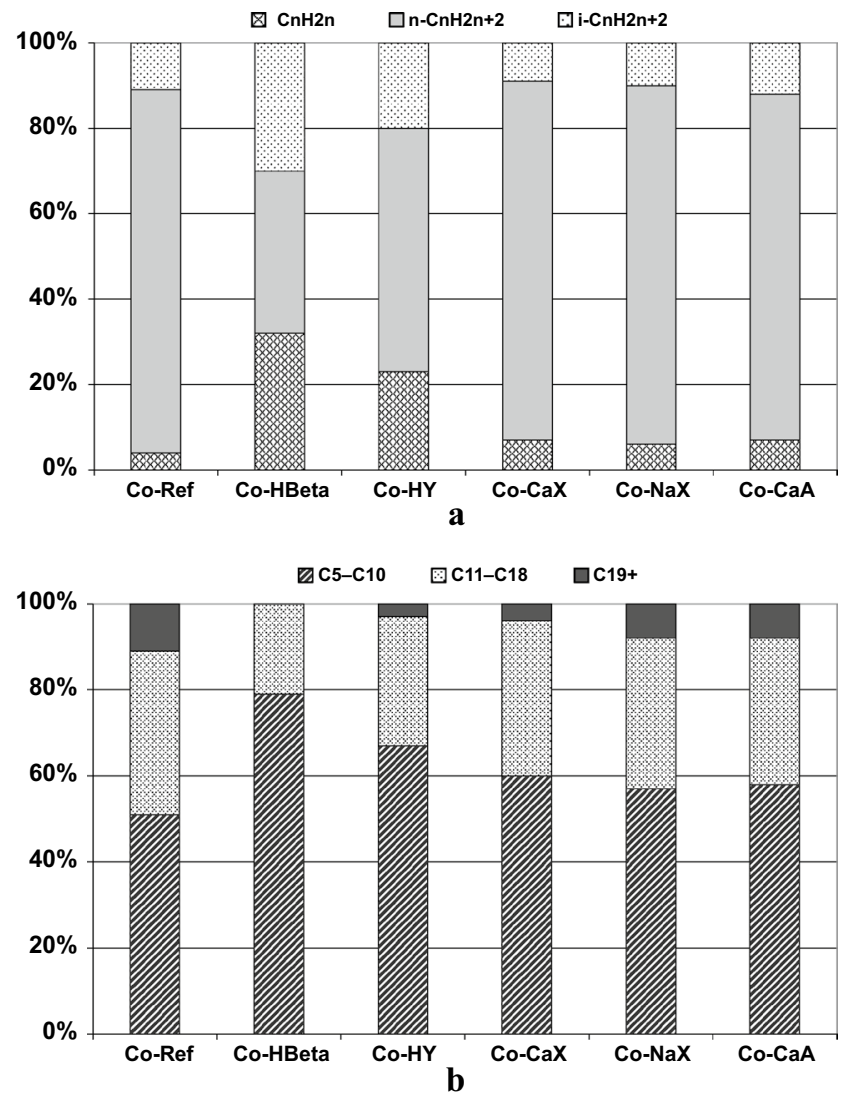

Fig. 6 Group and fractional composition of liquid syncrude synthesized in presence of different forms of zeolite

line with the effect of carbocation mechanism of secondary transformations of FTS-generated hydrocarbons in presence of H-zeolites and water as explained elsewhere [5-8].

Molecular-weight distribution of $n$-alkanes for Co-Ref, Co-HBeta and Co-CaA catalysts is shown in Fig. 7. The impact of zeolites is apparent especially in case of $\mathrm{H}$-form. It can be seen from Fig. 7 that the introduction of HBeta zeolite leads to sharp drop in the content of heavier alkanes and to general decrease in the content of normal alkanes in the syncrude.

The comparative stability (deactivation behaviour) of the catalysts under investigation was estimated by carrying out experiments with longer time on stream-see Table 3 . The Co-HBeta catalyst manifested the best stability among the others, i.e. its activity remained as high as $98 \%$ of initial one after $100 \mathrm{~h}$ on stream. Meanwhile, both Co-Ref and Co-CaX catalysts dropped their activity down to $87 \%$ level. The Co$\mathrm{NaX}$ manifested the lowest stability with $62 \%$ activity after $100 \mathrm{~h}$ on stream.

Besides, we observed that only in the presence of zeolites in $\mathrm{H}$-form the heat-conducting component (aluminium metal flakes) was not exposed to oxidizing effect of water under conditions of Fischer-Tropsch synthesis (Table 1) whereas 


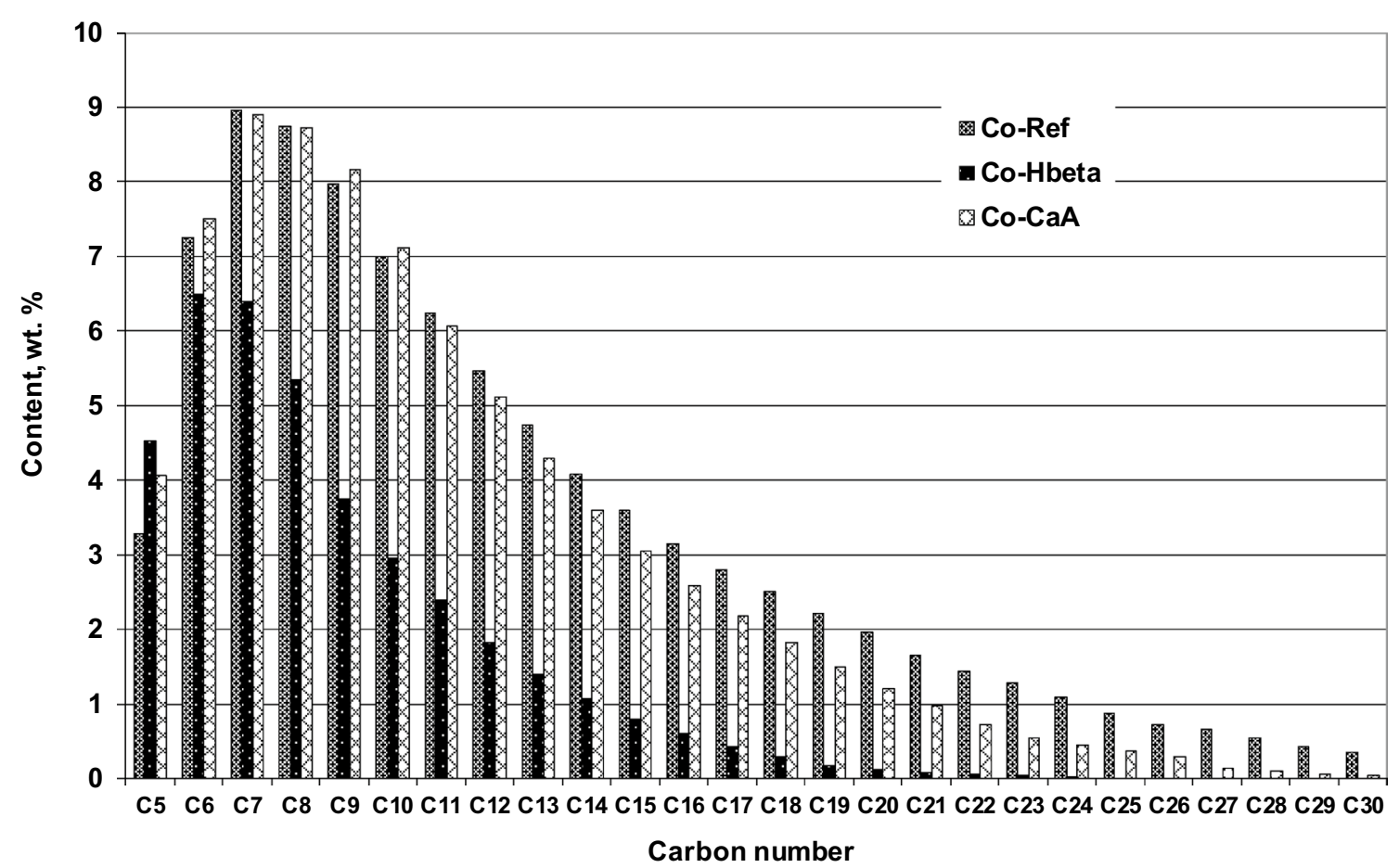

Fig. 7 Molecular weight distribution of $n$-alkanes in the syncrudes received over Co-Ref, Co-HBeta and Co-CaA catalysts

Table 3 Deactivation behavior of the catalysts under investigation after $100 \mathrm{~h}$ on stream

\begin{tabular}{lll}
\hline Catalyst & $\begin{array}{l}\text { Initial activity, mcmol// } \\
\left(\mathrm{s} \mathrm{g}_{\mathrm{Co}}\right)\end{array}$ & $\begin{array}{l}\text { Activity after } 100 \mathrm{~h} \text { on } \\
\left.\text { stream, mcmol/( } \mathrm{s} \mathrm{g}_{\mathrm{Co}}\right)\end{array}$ \\
\hline Co-Ref & 33 & 29 \\
Co-HBeta & 48 & 47 \\
$\mathrm{Co}-\mathrm{Ca} X$ & 65 & 57 \\
$\mathrm{Co}-\mathrm{Na} X$ & 63 & 39 \\
\hline
\end{tabular}

the catalysts with zeolites in cationic form as well as the reference catalyst showed sharp drop in the aluminium metal content after relatively short time on stream. It is possible to assume that degradation of heat-conducting additives affects the stability of work and service life of the catalyst. It is possible that zeolite in $\mathrm{H}$-form in a Co catalyst prevents oxidation of a heat-conducting component (oxidation of aluminium metal into alumina) because it involves water into secondary reactions, forming additional Bronsted acid centres and also providing protection for water-vulnerable surfaces by forming an intermediate hydrocarbon film. It is possible that $\mathrm{H}$-form zeolites help protecting Co particles from oxidation and sintering. In this respect it is interesting to compare TEM images of catalysts with different forms of zeolites after certain time-on-stream. Figure 8 shows TEM results for Co-HBeta with hydrophobic zeolite vs $\mathrm{Co}-\mathrm{CaA}$ with hydrophilic zeolite after $100 \mathrm{~h}$ on stream. As discussed in the "Introduction", hydrophobicity/hydrophilicity classification is based on competitive absorption of water from water-hydrocarbon mixtures [17-19]. The comparison of Co particle sizes suggests that $\mathrm{H}$-form zeolite hinders $\mathrm{Co}$ particle sintering under hydrothermal conditions of a Fischer-Tropsch bed. Indeed, while the as-synthesized catalysts are characterized by CO particle size of $10-15 \mathrm{~nm}$, the $100-\mathrm{h}$ run leads to approximately $20 \mathrm{~nm}$ in case of Co-HBeta vs $40-50 \mathrm{~nm}$ in case of Co-CaA.

The difference in hydrocarbon behaviour on the surface between hydrophobic and hydrophilic catalysts can be clearly seen in Fig. 9. Figure 6 shows SEM images of CoHBeta and $\mathrm{Co}-\mathrm{CaX}$ catalysts after catalytic run. Residual hydrocarbon on the surface of Co-HBeta forms rather dense protective coating while $\mathrm{Co}-\mathrm{Ca} X$ is characterized by scarce hydrocarbon spheres on the surface. EDX was used for identification of the hydrocarbon-covered surfaces. In addition, prolonged exposition to the impact of SEM electron beam resulted in melting of hydrocarbons, which was easily detected by eye. The after-melting hydrocarbon spheres on the surface of $\mathrm{Co}-\mathrm{Ca} X$ were seen as quick liquid drops.

Thus, the use of zeolites in Co catalysts of Fischer-Tropsch synthesis results in cooperative effect in the form of sudden increase of the zeolite activity in catalysing secondary transformations of FTS-generated hydrocarbons (cracking, isomerization, etc.) at untypically low temperatures. In addition, hydrophobic zeolites in $\mathrm{H}$-form allow changing hydrophobicity of the pore walls and influence 
Fig. 8 TEM images of the Co particles on the catalyst surfaces after $100 \mathrm{~h}$ on stream: a Co-HBeta with hydrophobic zeolite, b Co-CaA with hydrophilic zeolite
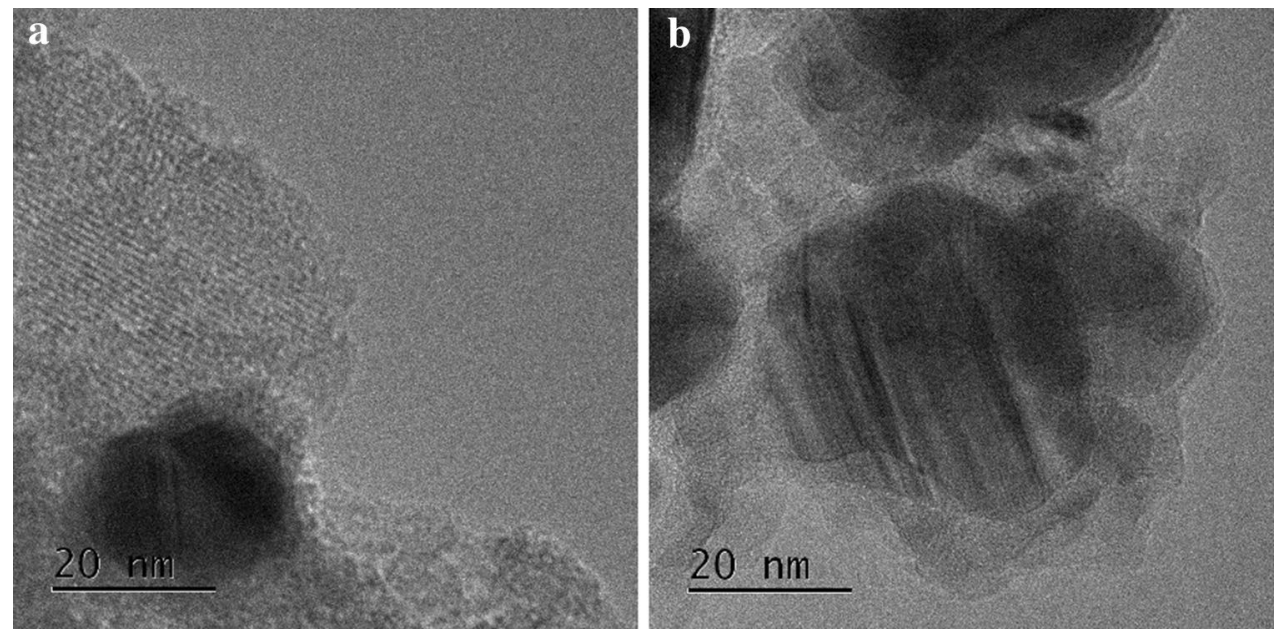
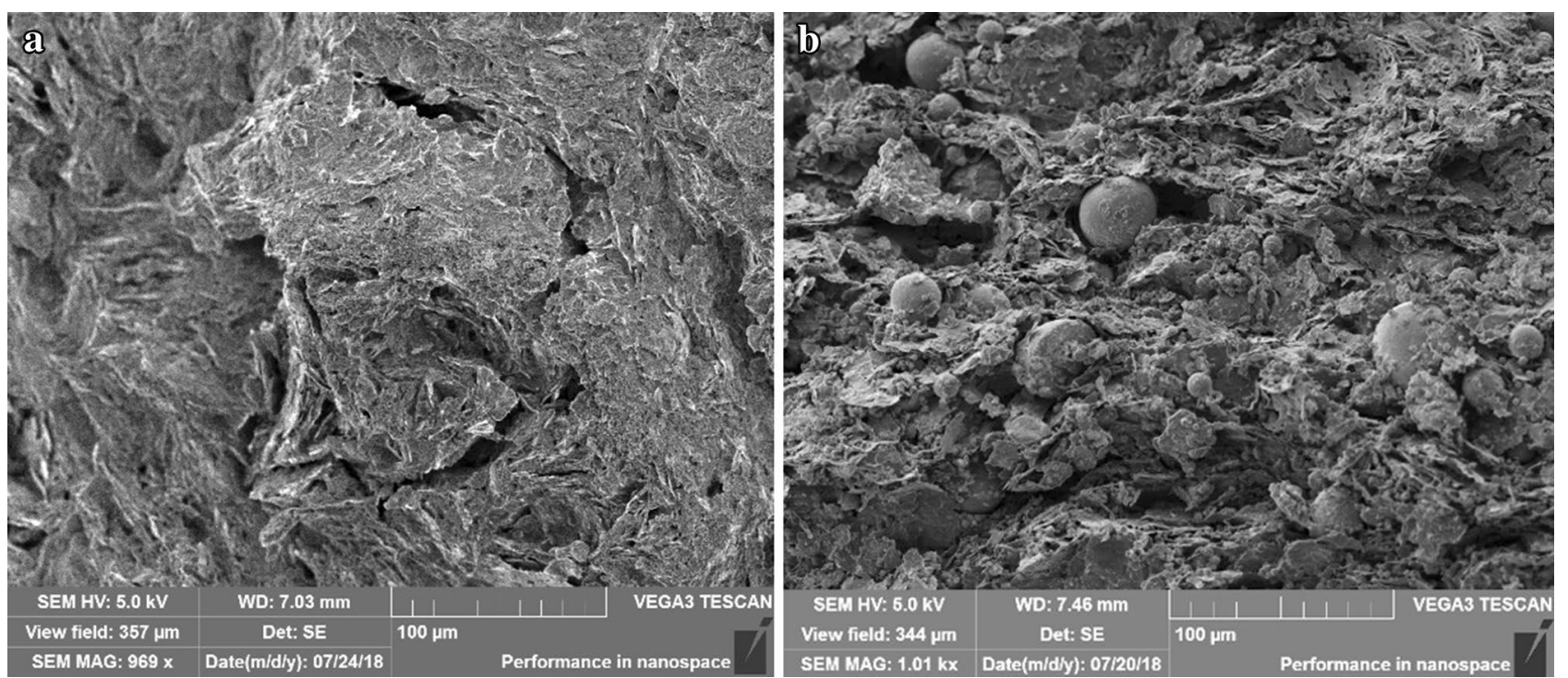

Fig. 9 SEM of the surface of the catalysts after Fischer-Tropsch synthesis run: a Co-HBeta with hydrophobic zeolite, b Co-CaX with hydrophilic zeolite

capillary condensation phenomena [19]. The most unexpected cooperative effect of $\mathrm{Co}$ and hydrophobic zeolites is the improvement of degradation behaviour of the catalysts due to involvement of FTS-generated water into formation of additional Bronsted centres [25-27] thus preventing undesirable oxidation of heat-conductive metal additives and other water-induced degradation processes.

\section{Conclusion}

The use of zeolites in Co catalysts of Fischer-Tropsch synthesis (FTS) results in cooperative effect in the form of sudden increase of the zeolite activity in catalyzing secondary transformations of FTS-generated hydrocarbons at unusually low temperatures. In addition, hydrophobic zeolites in $\mathrm{H}$-form allow changing hydrophobicity of the pore walls and influence capillary condensation phenomena for intermediate species. The most unexpected effect of Co and hydrophobic zeolites is the improvement of $\mathrm{Al}$ metal degradation behavior due to involvement of FTS-generated water into formation of additional Bronsted centers thus preventing undesirable oxidation and decreasing negative effect of water.

Acknowledgements The authors thank The Ministry of Science and Higher Education of Russian Federation for support in terms of the State Assignment to FSBI TISNCM.

Open Access This article is licensed under a Creative Commons Attribution 4.0 International License, which permits use, sharing, adaptation, distribution and reproduction in any medium or format, as long as you give appropriate credit to the original author(s) and the source, provide a link to the Creative Commons licence, and indicate if changes

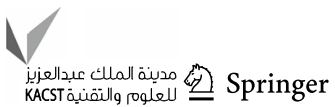


were made. The images or other third party material in this article are included in the article's Creative Commons licence, unless indicated otherwise in a credit line to the material. If material is not included in the article's Creative Commons licence and your intended use is not permitted by statutory regulation or exceeds the permitted use, you will need to obtain permission directly from the copyright holder. To view a copy of this licence, visit http://creativecommons.org/licenses/by/4.0/.

\section{References}

1. Ronald F, Probstein R, Edwin H (eds) (2006) Synthetic Fuels. New York, Courier Corporation, p 490

2. Maitlis PM, Klerk A (eds) (2013) Greener Fischer-Tropsch processes. In: Maitlis PM Chapter 1: What is Fischer-Tropsch? Wiley-VCH, Weinheim, pp 1-15

3. Dry ME, Steynberg AP (eds) (2004) Fischer-Tropsch technology studies in surface science and catalysis. In: Steynberg AP Chapter 1: Introduction to Fischer-Tropsch technology. Elsevier B.V., Amsterdam, pp 1-15

4. Lapidus AL, Krylova AYu (1998) Russ Chem Rev 67:1032

5. Sineva LV, Asalieva EYu, Mordkovich VZ (2015) Russ Chem Rev $84: 1176$

6. Wang Y, Wu H, Zhang Q, Tang Q (2005) Microporous Mesoporous Mater 86:38

7. Sartipi S, Parashar K, Valero-Romero MJ (2013) J Catal 305:179

8. Mordkovich VZ, Sineva LV, Kulchakovskaya EV, Asalieva EYu (2015) Catal. Ind. 15:23

9. Sineva LV, Khatkova EYu, Kriventceva EV, Mordkovich VZ (2014) Mendeleev Commun 24:316

10. Derevich IV, Ermolaev VS, Mordkovich VZ (2010) Proceedings of the 14th international heat transfer conference IHTC14, Washington, pp 1-10

11. Asalieva E, Gryaznov K, Kulchakovskaya E, Ermolaev I, Sineva L, Mordkovich VZ (2015) Appl Catal A 505:260
12. Website of INFRA Technology Ltd. (2019) http://infratechnology .com/. Accessed 10 Apr 2019

13. Bukur DB, Pan Z, Ma W, Jacobs G, Davis BH (2012) Catal Lett 142:1382

14. Ma W, Jacobs G, Ji Y, Bhatelia T, Bukur DB, Khalid S, Davis BH (2011) Top Catal 54:757

15. Borg Ø, Storsæter S, Eri S, Wigum H, Rytter E, Holmen A (2006) Catal Lett 107:95

16. Clayes M, Dry ME, van Steen E (2015) ACS Catal. 5:841

17. Olson DH, Haag WO, Borghard WS (2000) Microporous Mesoporous Mater 35-36:435

18. Stelzer J, Paulus M, Hunger M, Weitkamp J (1998) Microporous Mesoporous Mater 22:1

19. Yonli AH, Gener I, Mignard S (2010) Microporous Mesoporous Mater 132:37

20. Yu J, Luo J, Zhang Y, Cao J, Chang Ch, Gorte RJ, Fan W (2016) Microporous Mesoporous Mater 225:472

21. Kiselev AV, Lopatkin AA, Shulga AA (1985) Zeolites 5:261

22. Halasz I, Kim S, Marcus B (2002) Mol Phys 100:3123

23. Halasz I, Agarwal M, Marcus B, Cormier WE (2005) Microporous Mesoporous Mater 84:318

24. Kulchakovskaya EV, Asalieva EYu, Sineva LV, Mordkovich VZ (2017) Mend. Commun. 27:75

25. Hunger J, Beta IA, Bolhlig H, Ling CS, Jobic H, Hunger B (2006) J. Phys. Chem. B 110:342

26. Bolis V, Busco C, Ugliengo P (2006) J. Phys. Chem. B 110:14849

27. Parker LM, Bibby DM, Burns GR (1991) Zeolites 11:293

Publisher's Note Springer Nature remains neutral with regard to jurisdictional claims in published maps and institutional affiliations. 